\title{
Ramón Pérez de Ayala y el paisaje de alta montaña
}

\section{Ramón Pérez de Ayala and the high mountain landscape}

\author{
Jorge Canals Piñas ${ }^{1}$
}

Como citar este artículo: Canals Piñas, J. (2021). Ramón Pérez de Ayala y el paisaje de alta montaña, Pangeas. Revista Interdisciplinar de Ecocrítica (núm. 3) 48-60. https://doi.org/10.14198/PANGEAS.18816

\begin{abstract}
Resumen
Ramón Pérez de Ayala (1880-1962) se cuenta entre los raros escritores españoles contemporáneos en los que la naturaleza y el paisaje de montaña asumen un papel de relieve, cuanto menos en su primera fase de producción. Nuestro análisis parte de Tinieblas en las cumbres (1907), lo que nos permite adentrarnos en la sensibilidad que Alberto Díaz de Guzmán (alter ego de Pérez de Ayala y protagonista de la tetralogía juvenil del escritor asturiano) muestra respecto a la naturaleza. Tendremos asimismo en cuenta el conjunto de reportajes que Pérez de Ayala escribió en 1916, en el curso de una misión periodística que le llevó al frente alpino italiano, en calidad de enviado especial para los periódicos La Prensa (Buenos Aires) y El Imparcial (Madrid), durante el primer conflicto mundial. Un análisis comparado entre los textos nos permite examinar el cambio que en menos de una década se produce en la visión de Pérez de Ayala que, frente a la acción de las fuerzas oscuras de la naturaleza, parte de un posicionamiento inicial que pone al descubierto una actitud firmemente anclada en la tradición cultural latina y humanística. Ello no obsta para que apenas una década más tarde se produzca un cambio de perspectiva (condicionado por el pensamiento de Friedrich Nietzsche y la obra lírica de Gabriele D’Annunzio) que tiene mucho de ideológico: ensalzará entonces al hombre nuevo curtido en el conflicto guerrero y capaz de vencer a la naturaleza, que se erige como antagonista.
\end{abstract}

Palabras clave: Ecocrítica; Gran Guerra; Pérez de Ayala; Petrarca; Nietzsche; D’Annunzio.

\section{Abstract}

Ramón Pérez de Ayala (1880-1962) is among the few contemporary Spanish writers in whose texts mountainous landscape assumes a key role, mainly in his early works. Our analysis will take into account Tinieblas en las cumbres [Darkness at the Summit] (1907), primarily focusing on the nature awareness of Alberto Díaz de Guzmán, writer's alter ego and main character in the whole Pérez de Ayala's youth tetralogy. We shall also consider journalistic reportages written in 1916 by the Spanish author in the course of his assignment as special correspondent for newspapers La Prensa (Buenos Aires) and El Imparcial (Madrid) on the Alpine Italian frontline and during the Great War. Comparative analysis between texts provides us with valuable data that allows us to examine how Pérez de Ayala's initial approach to the blind forces of nature, deeply rooted in the Latin and humanistic intellectual heritage, reveals in less than a decade a major turnaround influenced by Friedrich Nietzsche's thought and Gabriele D’Annunzio's lyric poetry.

Key words: Ecocriticism; Great War; Pérez de Ayala; Petrarch; Nietzsche; D’annunzio.

1. Jorge Canals Piñas. Università degli Studi di Trento (Italia). jordi.canals@unitn.it https://orcid.org/0000-0002-9171-5620 


\section{LA MONTAÑA EN LA TRADICIÓN LITERARIA PENINSULAR}

La aproximación a los entornos montañeses y a los modos de vida rurales en aldeas de alta cota es un motivo inusual en nuestras letras. Con dificultad rastreamos una mínima fascinación o curiosidad de los escritores hispanos por tales paisajes. Y ni siquiera hoy, cuando el interés por cuestiones medioambientales ha estimulado el interés de la masa de lectores, apenas detectamos un fenómeno editorial similar al que se registra en Reino Unido o en Italia, donde las obras de autores como Robert MacFarlane, Paolo Cognetti o Mauro Corona, que han hecho de la montaña su objeto de indagación narrativa, escalan posiciones entre la lista de libros más vendidos en sus respectivos países y aun en traducción a otros idiomas. Incluido, paradójicamente, el nuestro.

Tampoco hallamos textos hispanos que encajen en dicha tipología entre la producción editorial europea de la segunda mitad de siglo XVIII, cuando la literatura de viajes empezaba lentamente a configurarse como género con rango literario propio y ya desligado de la escritura vinculada a la exploración geográfica o a la divulgación científica ${ }^{1}$. Ni siquiera los registramos en décadas sucesivas, cuando a medida que las colectividades rurales de alta cota se configuraban como enclaves antagónicos e impermeables a los avances de una sociedad industrial asimiladora que desde el norte del continente europeo irradiaba un nuevo modelo de desarrollo económico. Tal modelo se erigió como patrón que en buena medida determinó que obras nacidas a remolque del Romanticismo ${ }^{2}$, que delatan un

\footnotetext{
1. Es Ilamativo que para José Viera y Clavijo, en su Diario de mi viaje desde Madrid a Italia y Alemania (producto de un viaje realizado en el año 1780, por más que el texto se publicó póstumamente en 1849), el tránsito por los Alpes acabe reseñado en escasas líneas (1849: 22-23). Y más llamativo resulta si se tiene en cuenta que, para los viajeros británicos del Grand Tour, constituía aquella una de las etapas memorables del periplo europeo (Negrete Plano, 2002; Giacomoni, 2001: 44-46).

2. Una reconstrucción panorámica minuciosa de la percepción del paisaje de montaña, desde los inicios de la era moderna hasta llegar a la eclosión romántica, nos la da el brillante ensayo de Giacomoni (2001).
}

marcado interés por profundizar en la relación entre individuo y paisaje, llegaran a gozar de fortuna editorial en Occidente. Es el momento en que, por efecto de la incipiente industrialización, "el hombre ha ido descubriéndose a sí mismo. Ha surgido el yo frente al mundo; el hombre se ha sentido dueño de sí, consciente de sí frente a la Naturaleza" (Azorín, 1917: 14). Y, en cambio, por lo que se refiere a España, si exceptuamos a José María de Pereda, para quien la montaña cántabra sirvió de marco narrativo para su gran obra de ficción Peñas arriba (1895), el inventario arroja un balance editorial desolador. Desolador hasta el punto de que dicha circunstancia ha obligado a los historiadores de la cultura hispana, interesados en documentar la percepción de la geografía y cultura de alta montaña en nuestras letras $^{3}$, a rescatar textos y publicaciones escritas con un acentuado propósito científico y muy poco perceptibles pretensiones literarias. Es este, por ejemplo, el caso de Casiano de Prado (1797-1866), a quien su interés por la mineralogía le llevó a recorrer los Picos de Europa, y cuyos opúsculos se han convertido también en instrumentos con los que calibrar en parte el sentimiento del hombre contemporáneo hacia el paisaje de montaña.

En la lucha por la supervivencia de sociedades rurales inmutables frente al avance de una sociedad desarrollada, la sensación es la de que los autores decimonónicos peninsulares quedaron seducidos por el progreso resuelto de la sociedad industrial que, de manera lenta aunque constante, se iba afianzando también en nuestro país. Tan sólo el paisaje urbano, la metrópolis progresivamente cosmopolita y la geografía cultural en la que interaccionan gentes de muy distinta extracción, alcanzan a merecer rango de espacio narrativo por el que el individuo contemporáneo vaga como por los recovecos de un laberinto existencial. Y así hasta el momento de la eclosión de lo que se dio en llamar la Generación del 98, cuando Azorín, Pío Baroja, Miguel de Unamuno o Antonio Machado se lanzaron al consabido redescubrimiento del paisaje y de las poblaciones de la meseta castellana.

\footnotetext{
3. El recuerdo va sobre todo a la producción científica del geógrafo Eduardo Martínez de Pisón. Remitimos, en particular, al ensayo escrito a cuatro manos junto con Sebastián Álvaro (2010).
} 
Entre los autores peninsulares que a lo largo del siglo XIX cultivaron la literatura odepórica son de hecho excepcionales quienes dejaron constancia en sus textos, antes de que la sociedad industrial incipiente cancelara su recuerdo para siempre, de modos de vida arcaicos que resistían en enclaves alejados de las rutas más transitadas. Cabe recordar, al respecto, a Enrique Gil y Carrasco, quien recorrió la montaña berciano-leonesa para el Bosquejo de un viaje a una provincia del interior (1843), así como para unos pocos artículos de cariz costumbrista que habían aparecido años antes en las páginas del Semanario Pintoresco Español (1839) ${ }^{4}$.

Por su parte Pedro Antonio de Alarcón, uno de nuestros más exquisitos paisajistas, se adentró en las asperezas de la Sierra Nevada granadina que sucesivamente describió en la obra que lleva por título La Alpujarra (1874). En fecha reciente nos hemos aproximado (Canals, 2016), al estudio de la sugestiva descripción de la geografía alpina que Alarcón incluyó asimismo en De Madrid a Nápoles (1861), otro de sus excelentes textos de viajero. En aquellas páginas retrató con todo pormenor el valle de Chamonix, el cantón suizo de Valais y la montaña piamontesa y lombarda, lo que nos ha permitido calibrar una insólita sensibilidad por unos paisajes y tradiciones etnográficas desatendidos por los autores hispanos del siglo XIX y décadas sucesivas.

El estallido del primer conflicto mundial hizo que el enviado especial de las grandes cabeceras periodísticas españolas, esa aún novedosa figura profesional surgida pocas décadas antes $^{5}$, se aproximara a la fuente de la noticia bélica, compartiendo el campamento militar con oficiales y soldados. Quienes se desplazaron a escenarios de contienda de fuerzas armadas beligerantes tomaron así contacto con espacios

\footnotetext{
4. Véase el estudio de Álida Ares (2014) que precede a su edición de la prosa periodística de Enrique Gil y Carrasco. Azorín reconoce al escritor berciano el mérito de que "en las páginas de este libro [EI Señor de Bembibre (1844)] nace por primera vez en España el paisaje en el arte literario" (Azorín, 1917: 19-20).

5. Aunque ganó popularidad a raíz de la Guerra de Crimea, su espacio profesional quedó plenamente acotado en el transcurso de la Guerra de Secesión estadounidense (McLoughlin, 2009).
}

geográficos desconocidos para la mayor parte de los lectores de la prensa peninsular: los bosques de Bélgica, así como las llanuras del norte de Francia limítrofes con las tierras invadidas por las tropas ocupantes alemanas. Y también (aunque cabe admitir que con una frecuencia menor a la de los frentes ya mencionados) con la barrera alpina que se interponía entre los ejércitos de la Austria Imperial y del joven Estado italiano.

Sin excepción los enviados especiales españoles quedaron magnetizados por aquella lucha épica que estaba teniendo lugar en las crestas de los grandes macizos alpinos. Sin excepción dieron cabida en sus reportajes a la descripción maravillada de aquel insólito escenario bélico en el que transcurrió la denominada guerra blanca. Así Juan Pujol (18831967), enviado especial de $A B C$ que, tan pronto como Italia declaró la guerra a Austria, se desplazó junto con las tropas imperiales e informó desde las trincheras austríacas del Isonzo y de la Carnia en verano de 1915 (González, 2016). Así también Ramón Pérez de Ayala (1880-1962) ${ }^{6}$, Eduardo Gómez de Baquero (1866-1929) y Enrique Díaz-Retg $(1883-1963)^{7}$ quienes un año más tarde, viajando en comitiva y tras aceptar una invitación oficial procedente de la oficina de prensa del Alto Mando italiano, recorrieron el frente kárstico y dolomítico.

En el presente trabajo consideraremos los artículos que Ramón Pérez de Ayala escribió desde el frente italiano para el periódico madrileño El Imparcial y para el bonaerense La Prensa (artículos que en su mayor parte confluyeron más tarde en el volumen titulado Hermann encadenado [1917]), cotejando las descripciones de montaña con las que respectivamente aparecen en Tinieblas en las cumbres (1907) [TC], que fue su primera novela extensa publicada una década antes y en la que, como queda dicho, el paisaje cumple una función primaria en el desarrollo de la ficción narrativa.

\footnotetext{
6. De los que se desplazaron al frente italiano es el autor que más atención ha merecido por parte de los investigadores. Véanse, al respecto, los trabajos de Dougherty (2012), González (2012) y Honrado de la Torre (2016).

7. En Canals (2017) se han analizado y editado críticamente el conjunto de reportajes que escribió este reportero barcelonés, redactor del periódico obrero El Diluvio y enviado especial al frente italiano.
} 


\section{HACIA UN REENCUENTRO ARMÓNICO CON LA NATURALEZA}

Aunque en el presente trabajo el foco de atención estriba en los artículos del asturiano Ramón Pérez de Ayala desde el frente italiano, precisamos aproximarnos a sus novelas precedentes. Y es que, dado su origen, el paisaje montañés no fue para este escritor una dimensión espacial desconocida. Desde el arranque de su producción narrativa, las montañas de la cordillera asturiana asumieron un papel de relevancia en la construcción de un espacio narrativo acorde a las tribulaciones existenciales de sus personajes protagonistas $^{8}$. Y la referencia es, sobre todo, a su ópera prima: la novela titulada Tinieblas en las cumbres [TC], con la que en 1907 Ramón Pérez de Ayala dio inicio a la tetralogía con la que se propuso seguir el proceso formativo de su alter ego Alberto Díaz de Guzmán (Amorós, 1972: 84).

Pese al aparente estilo desenfadado y a su lenguaje festivo, hay en TC algo progresivamente turbador en cuanto narra en el pormenorizado relato del ascenso a lo alto del puerto de Pajares por parte de la comitiva de crápulas, a los que se suman las pupilas del burdel de la ciudad de Pilares [Oviedo], que hasta allí se encaminan con la finalidad de contemplar un eclipse solar desde las cumbres más altas de la cordillera. Un acontecimiento astronómico fuera de lo común y a cuya fascinación, lindante con la catástrofe natural y la toma de conciencia frente al caos cósmico, el personaje protagonista terminará sucumbiendo hasta alcanzar estado de trance y caer en sucesiva postración existencial. Con lo que de algún modo culmina el tránsito a la madurez de Alberto, protagonista de la mencionada tetralogía y en la que revela profundas inquietudes estéticas.

Al recrear este ascenso, que tanto tiene de proceso purificador, hay una marcada voluntad simbolista. Todos y cada uno de los motivos narrativos que entran en juego en este viaje a las alturas acabarán adquiriendo una significación en clave. También el tren en el que embarcan,

\footnotetext{
8. También en su obra poética, lo que abordó ya Ángel González en un artículo de homenaje donde hace hincapié en cómo la naturaleza es para Pérez de Ayala "símbolo del misterio, espejo, manifestación o incluso tangible presencia de la divinidad" (1981: 148).
}

en la estación de Pilares, quienes constituyen un desenfadado grupo de amigos. El tren es el vehículo destartalado, triste y taciturno (por recurrir a la adjetivación con que lo califica el narrador al inicio del viaje [TC: 172]) que los va a trasladar en el transcurso de la noche a la soledad de la montaña cantábrica por la que los miembros de la comitiva festiva (cuyos deseos exclusivos eran los de dar rienda suelta a sus instintos más primarios y lejos de la capital de provincias) vagarán desorientados ${ }^{9}$. Más allá de que el ferrocarril en sí mismo se erija en quintaesencia de una sociedad abocada a la industrialización (Litvak, 1991), a lo largo de las peripecias narrativas va tomando mayor carga icónica al ser el medio a bordo del cual los pasajeros abandonan la ciudad y se internan en las asperezas de los montes asturianos.

Constituye este un viaje que, cuanto menos en el caso del personaje protagonista, tiene mucho de iniciático. Alberto encarna al individuo que sale de su cobijo urbano, en el que han transcurrido sus primeros años de juventud viviendo con total despreocupación, y que ahora deja a sus espaldas para ir en búsqueda de la soledad de los montes. En aquel punto limítrofe con el páramo leonés sufre toda una transformación existencial; hasta el punto de que, al cabo de aquella larga jornada, regresará con ánimo angustiado a su punto de partida y dejando que aflore al exterior una personalidad muy distinta a la del personaje protagonista que empezó a tomar cuerpo al inicio de TC. A bordo del ferrocarril, y en el corazón de la noche, arranca una expedición que aproxima al protagonista hasta un lugar enclavado más allá del límite de la civilización urbana y que concluirá asimismo en una noche lóbrega, que no es más que extensión de la crisis existencial en la que ha quedado sumido el ánimo de Alberto. Todo un viaje circular de ida y vuelta al lugar de partida, al

\footnotetext{
9. Salvo en el caso de Alberto, Yiddy y de su compañero Travesedo, ningún otro de los componentes de la pandilla muestra una brizna de sensibilidad estética hacia aquel entorno natural, pues tal como el autor de la novela deja en claro, "eran individuos para quienes el mundo exterior, la grande obra terrible y aparentemente inanimada de la naturaleza, no tenía vida propia ni finalidad evidente, como no fuera la de subvenir a las necesidades humanas" (Pérez de Ayala, 1971: 234).
} 
cabo del cual Alberto conseguirá despojarse, por fin, del hombre viejo y revestirse (de manera casi agustiniana y tras el debido ascenso expiatorio) con las cualidades del hombre que afronta el futuro con una voluntad decidida de redención.

La excursión resume un ascenso simbólico y de expiación espiritual. Constituye un acto que Alberto lleva en cabo casi en soledad, acompañado por la redimida Rosina y, en algunos trechos del camino, por Adam Warble (que se presenta afablemente como Yiddy) y Travesedo, sus compañeros de viaje más reflexivos y con los que consigue una mayor sintonía intelectual. Mientras que el resto de componentes de la alegre y despreocupada comitiva van quedando rezagados, deseosos de refocilarse en las casucas que encuentran a pie de sendero y en las que se guarecen para apurar cuartillos de vino, continuar con las chanzas y hasta cantar al son de una guitarra. Durante el ascenso, una vez cede Alberto a la tentación y entra en uno de los tugurios, pero de inmediato sale de nuevo al exterior, como asfixiándose en aquel aire "impuro" (y es ese justamente el adjetivo con el que describe el ambiente enrarecido que le asalta en el interior de la venta de Panzina [TC: 267]) donde la mayor parte de los compañeros de excursión se entrega a la bebida entre arrieros, serranos y otros urbanitas tan curiosos como ellos que a Pajares han acudido para observar el eclipse. Y, una vez al aire libre, le tocará aún a Alberto sortear a las gentes aquejadas de tuberculosis que a sus puertas también remolonean a aquella hora temprana de la mañana: "atacadas de terrible mal, las cuales buscaban un alivio, o acaso ilusoriamente curación completa, en las alturas del puerto" (TC: 268). De algún modo es como si la predestinación impidiera a Alberto una cómoda evasión frente a los males que aquejan al mundo y una y otra vez se le forzara a contemplar la enfermedad de la vida.

Alberto sigue imparable el ascenso hacia la cumbre y en compañía de Yiddy, con quien ya antes ha mantenido un largo coloquio superfluo (TC: 245-265) en el transcurso del cual la argumentación dialéctica ha gravitado en torno al reino de la naturaleza y a la relación que el artista debe con ella entablar. A lo largo de dicha conversación, ha admitido Alberto que el contacto estrecho y ensimismado con ella le ha llevado a un estado de desasosiego místico: "puedo asegurarle que me encontraba confundido y así como disuelto en un espíritu o gran alma universal" (TC: 248-249).

Hay una pincelada de dialéctica oriental en ese choque que se produce entre el idealismo de Alberto (idealismo que se sublima en la contemplación ensimismada del paisaje) y la fuerza antagónica que le contrapone Yiddy, el cual lo hunde en la realidad más cruelmente terrena. Mientras a su alrededor discurre despreocupada y feliz la existencia de quienes, ciegos al destino del hombre, se complacen en apurar con deleite el momento presente. Y caminan estos desorientados por los declives de la montaña, intentando avanzar bajo la llovizna y por entre la espesísima niebla: "de suerte que nuestros amigos, los cuales andaban desparramados y en gran confusión, por saber los unos de los otros veíanse en el caso de dar grandes gritos; luego guiábanse hacia el manantial de donde la voz partía" (TC: 265). Al igual que naves que navegan sin rumbo y accionan de continuo la sirena para evitar el choque con otro buque, tal como la voz narrativa describe echando mano de un símil náutico.

En lo más alto de las estribaciones de la cordillera se librará Alberto a la observación del fenómeno del eclipse que lo ha atraído hasta aquellas cumbres. Y lo hará con una rara angustia existencial, como necesitado de experimentar la crueldad de la que es capaz una naturaleza que puede llegar a ser violenta y cruel. Contempla el avance de la oscuridad en pleno día, mientras se halla en las estribaciones más altas, allí donde una línea divisoria delimita los paisajes antagónicos del páramo leonés hacia el sur y de los valles asturianos hacia septentrión. Pero sin deleitarse ya ante el contraste que tanto lo había deleitado en un primer momento (TC: 271-273). Sólo las tinieblas que avanzan, y que paradójicamente le iluminan interiormente, atraen ahora su atención hasta provocar el enajenamiento de su conciencia (TC: 279): Sacábale de su mutismo y distraimiento algún
rayo de sol que rasgara las nubes, muy de tarde
en tarde, y entonces volvíase hacia el cielo con
el semblante lleno de ansiedad. La sombra, o
más bien penumbra cárdena, que insidiosa y
paulatinamente setendía sobre la tierra, metíasele
a él por el espíritu y le enturbiaba el corazón.
Había bajado la temperatura en considerable 
medida, y parecía correr un escalofrío trágico por la epidermis terrestre, erizándola de terror.

Tras la visión de una naturaleza destructora y sublime ante la que el reino animal sucumbe y el individuo se descubre a sí mismo anonadado y empequeñecido, queda Alberto conmocionado. Algo de lo que el protagonista toma conciencia de modo doloroso y cayendo presa de una total perturbación que acabará transformándolo.

Se revelaesta experienciacomo una "reconquista del yo", por apelar a un tema recurrente en el ideario de Pérez de Ayala y sobre el que años después tejerá el escritor asturiano una sintética reflexión crítica en la que diseccionará la relación del individuo contemporáneo enfrentado a las potencias que se ocultan en la naturaleza (Pérez de Ayala, 1926).

Quien haya leído la epístola de las Familiares (IV.1) en que Francesco Petrarca describe la ascensión al Monte Ventoux (Petrarca, 1978: 255-269), en compañía de su hermano Gherardo, advertirá una inquietud espiritual compartida en el texto de Ayala. Nada casual, si se tiene en cuenta que, dos décadas después, el escritor asturiano admitirá en su prólogo a la mencionada obra de Díaz Caneja (Pérez de Ayala, 1926) el valor de este poderoso texto latino en el que el humanista toscano vuelve a enlazar intelectualmente con el culto a la naturaleza del clasicismo latino. Yello tras el largo paréntesis de la alta Edad Media cristiana occidental, cuando el individuo se mantuvo a distancia de aquel reino de la naturaleza salvaje en el que tantos motivos diabólicos y/o sacrales creyó haber identificado. Parafraseando la epístola latina, escribe Pérez de Ayala (1926: 49):

\footnotetext{
Avanza [Petrarca] ladera arriba, a costa de grandes fatigas y penalidades. Ya está en la cumbre, con las nubes a sus pies. Es como un endiosamiento. La naturaleza va a apoderarse de él. Pero en este instante Petrarca se recoge en sí, y ve desfilar ante su imaginación, como de presente, su vida pasada; todas las locuras que había cometido, y la moraleja de cordura, por ellas engendrada.
}

Es como si en estas escasas líneas el escritor asturiano quisiera sintetizar, con escrupulosidad fidelísima, la conversión del protagonista de TC tras haber tomado conciencia de sus propios demonios de juventud. $Y$ se produce allí, en las alturas del puerto de Pajares, donde Alberto admite por fin que: "hoy los siete sellos del libro de la sabiduría se han roto para mí. Y dentro no había sino desolación y tinieblas" (Pérez de Ayala, 1971: 291). Constituye el gozoso corolario de un acto expiatorio que no podría haberse llevado a cabo sin este contacto directo con la visión de las cumbres y bajo los efectos del eclipse que tanto lo ha conmocionado.

\section{UNA NATURALEZA COLONIZADA}

En los reportajes periodísticos de Ramón Pérez de Ayala, escritos en septiembre de 1916 (si bien estos se fueron publicando también, de manera diluida, a lo largo de 1917, año en el que terminaron asimismo recogidos en el volumen que lleva por título Hermann encadenado ${ }^{10}$ ), se entrecruzan dos filones temáticos aparentemente antagónicos: el aprecio estético por la wilderness alpina y la justificación de la campaña bélica del bando italiano que, en su mayor parte, tiene lugar en las estribaciones montañosas dolomíticas y que comporta la destrucción del entorno natural.

De acuerdo con una visión determinista muy del gusto de Ramón Pérez de Ayala en aquellos mismos años, y que da fundamento explícito al conjunto de textos periodísticos nacidos en los campamentos militares italianos, el espacio condiciona de manera intensa la personalidad del individuo. Según sea el hábitat en que un pueblo (o raza, por recurrir a un sustantivo muy marcado desde el punto de vista semántico y al que Ayala recurre en estos textos sin ningún tipo de contención) se ha generado y en el que transcurre su existencia, este proyectará un ideal paisajístico a la medida de sus aspiraciones humanas. Parafraseando al autor asturiano, allí donde el paisaje es de extremada austeridad y pobreza, sus gentes tienden a espiritualizarlo, a conferirle una dimensión casi mística; para quien ha nacido, en cambio, en entornos dominados por la montaña que clausura su horizonte mental, pesa cuanto hay de kolosal y enorme, cuanto

10. A quienes deseen reconstruir las vicisitudes editoriales, en el paso de la publicación de los artículos periodísticos a su inclusión final en el volumen recopilatorio, remitimos al estudio fundamental de José Ramón González (2012: 155-159). 
hay en él de sublime y cuyo carácter deriva de su belleza y también del terror que aquel paisaje inspira (Pérez de Ayala, 1917: 60). Dos visiones contrapuestas del entorno natural a las que el individuo se vincula, de acuerdo con su pertenencia al respectivo grupo étnico con el que se identifica, y que han terminado marcando un ideal estético en las diferentes culturas occidentales. También en las que conforman la geografía peninsular: los rasgos paisajísticos de buena parte de la meseta castellana, frente a los de los valles que asoman respectivamente al Cantábrico. Una contraposición ambiental, y por ende étnica, a cuya contemplación ensimismada sucumbe Alberto, el protagonista de $T C$, al recorrer la línea divisoria entre las provincias de León y Asturias:

\begin{abstract}
En aquellas cumbres, por el contrario, la mente sentíase sobrecogida y el juicio suspenso. Según se mirase al Mediodía o al Septentrión, y a partir de una raya neta, recortada definitiva, que es la que deslinda las vertientes o cuencas hidrográficas, lo que por una parte, hacia el Sur, era desolación y yermo y taciturnez terribles, era a la parte opuesta, hacia el Norte, exuberancia y frondosidad y jugo y color (Pérez de Ayala, 1971: 272).
\end{abstract}

Confiere singularidad a los textos de aquellos años iniciales de la producción periodística y narrativa del autor asturiano esta visión con fundamento intensamente étnico y en el que late un marcado determinismo social de cuño darwinista. Hasta el punto de que para Pérez de Ayala el primer conflicto mundial es, a su modo, el desenlace consecuente de dos civilizaciones que han mantenido a lo largo de los siglos dos posiciones diametralmente antagónicas respecto al entorno en que surgieron, crecieron y se desarrollaron. Algo que, a su parecer, se manifiesta en la guerra que se desencadena en las montañas del arco alpino. Hay, por un lado, la actitud de los pueblos latinos que aspiran, ante la sublimidad de una naturaleza kolosal, a anular cuanto de materia bruta se manifiesta en ella. Lo que tiene como consecuencia inmediata el hecho de que los mencionados pueblos latinos no dudan en doblegarla, en “urbanizarla” (Pérez de Ayala, 1917: 74) en cuanto se les presenta ocasión: hasta sus más altas cumbres han abierto una red de carreteras por las que viajan los convoyes militares, mostrando la misma obstinación con la que antaño los latinos proyectaron una red capilar de calzadas que, partiendo de Roma, se adentraban en parajes bárbaros e inhóspitos a los que su esfuerzo y tenacidad lograban al fin someter.

En la vertiente opuesta, subyace el gusto germánico por la preservación del entorno natural, según el cual la materia bruta es bella en sí misma, pues sumido en la wilderness el individuo queda enajenado y embargado por su "serenidad y grandeza", ensimismado hasta tal punto con la naturaleza ${ }^{11}$ que en ella termina naufragando y diluyendo su conciencia humana sin oponer resistencia (Pérez de Ayala, 1917: 60; v. Amorós, 1972: 100 y 463). Deahíque el individuo germánico (del que Hermann, el personaje paradigmático de raza que aparece ya en el título del volumen recopilatorio de los textos periodísticos, constituye cifra quintaesenciada del grupo étnico nacional) se resista con todas sus fuerzas, en opinión del escritor asturiano, a humanizar y civilizar el entorno, aspirando en cambio a hacerse uno con la naturaleza y, al cabo, a despojarse de sus rasgos individuales para entregarse a ella. Para el germano todo apunta, en definitiva, a la cancelación del individuo, a la conversión en "materia bruta"12. Apunta, en definitiva, a la "anulación" del individuo (Pérez de Ayala, 1917: 60), la misma tentación de la que es víctima Alberto al alcanzar las cimas de Pajares desde donde contempla los contrastes paisajísticos diametralmente antagónicos de las geografías castellana y asturiana. Constituye

11. Dejamos constancia de un opúsculo (anónimo, por más que Amorós [1972: 449-450] ha demostrado ser el resultado de la labor editorial de Ramón Pérez de Ayala) que circuló por la Península tras el estallido de la guerra y en el que, entre otras muchas declaraciones del Káiser, el asturiano incluyó la siguiente: "A través de las centurias pasadas, parece que como un cierto espíritu ha embebido y saturado el carácter teutónico, y es el amor a la naturaleza, que el Creador ha inculcado en nuestros corazones a manera de primogenitura de todos los alemanes" ([Pérez de Ayala], 1915a: 50).

12. Hasta no duda Pérez de Ayala en recurrir a una metáfora ejemplificadora vinculada semánticamente a las bellas artes: allí donde, según el sentir de los latinos, la naturaleza ha de transformarse por mano del hombre en escultura armónica, el germano ve en la naturaleza salvaje un monumento en sí mismo. 
una tentación contra la que Yiddy, que en su condición de británico conoce bien ese peligro (por haberlo experimentado antes en sí mismo, tal como confiesa a Alberto), le pone reiteradamente en guardia a lo largo del mencionado coloquio superfluo, en cuyo transcurso advierte: "ese indecente vicio de metafisiquear y neoplatonizar a solas con la naturaleza es el peor de todos los vicios y el que conduce a más miserable vida" (Pérez de Ayala, 1971: 250).

En calidad de enviado especial, Ramón Pérez de Ayala lo registra todo desde una plataforma de observación muy subjetiva. Invitado por el Alto Mando del ejército italiano, se mueve exclusivamente por entre las filas de las tropas de este país, sin establecer ningún contacto con los adversarios austro-alemanes, salvo el esporádico y superficial que se produce con los enemigos que se hallan internados como prisioneros en el campo de concentración y que, en la descripción de Pérez de Ayala, merecen apenas ser descritos en el relato del periodista asturiano, quien los reduce a mera condición de Untermenschen ${ }^{13}$ (Pérez de Ayala, 1917: 128-129):

A la mayor parte de los prisioneros se les ve que están deglutiendo, o mejor dicho, rumiando, pues en lugar de mover la mandíbula verticalmente, la mueven en un sentido transversal, con oscilación continua y perezosa. Este pequeño pormenor define cabalmente la sensación vaga que los prisioneros austriacos provocan. Es esa sensación de filosófico reposo, de enorme sosiego y olvido de todo, de gozo callado, que adivinamos en el turbio espíritu de algunos rumiantes, las vacas matronas y los bueyes cansinos. Es la sensación de beatitud horaciana tras del horror pánico y el furor homérico.

13. Con toda intencionalidad recurrimos a este término ya que Pérez de Ayala muestra, en años posteriores a la Gran Guerra, estar a su vez muy familiarizado con la obra de Friedrich Nietzsche, sintiendo atracción (y, al mismo tiempo, tomando debidas distancias hasta adoptar incluso un registro sarcástico) hacia el concepto de Übermensch o superhombre (Pérez de Ayala, 1921, 1922a-b). La huella de Nietzsche en la obra del asturiano resulta ostensible en sus novelas poemáticas y, de modo especial, en Prometeo (Leyra Soriano, 1998), que se publicó por vez primera en 1915, pocos meses antes de que se produjera el viaje al frente bélico alpino.
Cuando Pérez de Ayala se desplaza por las primeras líneas del frente, el enemigo en combate no es más que una presencia latente a la que sólo cabe intuir bajo la vegetación tupida de la comarca del Isonzo o camuflado en las grietas de la roca dolomítica. Es un enemigo invisible capaz de mimetizarse con aquel grandioso medio ambiente natural y cuya presencia intangible turba, y no poco, al reportero que escruta los bosques donde se agazapa el adversario. Al que define como adversario no sólo por su acción bélica hostil a los aliados, sino también por los principios a los que étnicamente se adscribe.

Por el contrario los italianos (o quizás quepa más bien decir, los latinos de quienes los italianos contemporáneos se revelan sus dignos descendientes directos, según opinión de Ayala), con los que por unas semanas tiene la dicha de compartir aquella singular guerra de montaña, son individuos incansables en su afán por transformar y "urbanizar" el entorno (Pérez de Ayala, 1917: 74); incansables en su afán por extender hasta las alturas, antaño inaccesibles, pistas de montaña que permitan dar cómodo asiento a una posición de dominio militar frente al enemigo. $Y$ todo ello en un entorno magnífico y sublime, cuyas quebradas sobrecogen por su perpendicularidad, y al pie de cimas ante las que el individuo siente la pequeñez de la condición humana como en ningún otro lugar de la tierra. Son individuos minúsculos, pero infatigables. La raza opone ante aquel reto titánico sus mayores méritos. Tanto que Pérez de Ayala asimila los soldados italianos a hormigas, a abejas, a organismos coralinos que en el ejercicio de su actividad incansable consiguen doblegar y transformar la naturaleza (Pérez de Ayala, 1917: 62 y 74). Nadie, a debida distancia, advertirá apenas movimiento alguno en aquella colectividad bien organizada que se aplica de manera diligente a la guerra industrial ${ }^{14}$. Allí donde el enemigo resiste quietamente a las acometidas vitalistas del rival italiano, este

\footnotetext{
14. No es nuestro dicho sintagma, sino que lo adoptamos de Leed (1981). Respecto a las "organizaciones sociales operativas y eficaces" cuyo paradigma (Gran Bretaña y Estados Unidos) tanto admiraba Pérez de Ayala, remitimos a González (1993: 20) y a Coletes Blanco (1984).
} 
opera en cambio en un entorno "animado" (en el sentido más etimológico del término) y pletórico de vida (Pérez de Ayala, 1917: 62).

Configura todo ello un peculiar punto de vista al que da estímulo una visión de la sociedad intensamente etnicista. El periodista asturiano sublima un espíritu latino y racial antagónico al espíritu teutón (González, 2012: 170-172). Y ello, por añadidura, en un momento histórico en el que, al sur del continente europeo, se impone un canon esteticista mediterráneo que, concertando la armonía y luminosidad propia de las tierras latinas, aspira a contraponerse a cuanto de "formidable, abrupto y selvático" (Pérez de Ayala, 1917: 60) proyecta el ideal paisajístico de la cultura germánica.

Para Pérez de Ayala, en la sociedad colectivista que encarnan las tropas italianas late una idea utópica. Son gentes que encarnan al hombre de acción y que operan en la adversidad, las cuales se hallan permanentemente en lucha contra la wilderness de los bosques de altura donde, por añadidura, se encuentran bajo el fuego del enemigo imperial. Su actividad laboriosa consigue que todo cuanto pudiera parecer "inerte" (Pérez de Ayala, 1917: 62-63) se pliegue a su voluntad. Allí en la espesura ha crecido una ciudad nueva, con todas las características urbanas que caracterizan a la arquitectura de la metrópolis, con sus habitaciones, refugios, portezuelas, tejados, ventanas, corredores, patios "de una casa de vecindad", establos... (Pérez de Ayala, 1917: 63). Colonizar el entorno alpino salvaje constituye, para el autor, el logro de la suprema raza latina que impone su voluntad y que lo transforma todo a su paso, arrollando al adversario con su ingenio portentoso e invencible. Para los latinos no tiene sentido sucumbir a la fuerza de la montaña, ni preservar la naturaleza selvática bajo cuyo influjo pernicioso han caído los teutones mostrando así la fragilidad de su raza. Y es que para Pérez de Ayala cabe, tan sólo, la "sensibilización" de una naturaleza que es "inerte", la "animación absoluta de la montaña" (Pérez de Ayala, 1917: 63).

El asturiano se solaza en una estampa antrópica de la naturaleza y del paisaje alpino. Si asimilación hay al mundo animal, en algún momento del relato argumentado de Pérez de Ayala, es como se ha visto para con aquellos seres que -como las hormigas, las abejas o los organismos coralinos- muestran un instinto innato hacia la organización colectiva y que, con su lenta acción, acaban asimismo socavando y transformando el paisaje, siendo ese mismo el proceder de las tropas italianas.

El ideal ambiental de Pérez de Ayala es el de un entorno en el que el hombre se halla siempre presente. Nada, pues, más alejado de su concepción ambientalista que el ideal que inspiró a los norteamericanos que partieron para explorar las vastas tierras del interior de su país y que quisieron a todo coste preservar su wilderness original, evitando contaminar aquella naturaleza virgen impidiendo con reglamentaciones su colonización (Garrard, 2004: 69-70). El ideal del asturiano es el de una naturaleza en la que el hombre avanza y proyecta también en ella su colectivismo metropolitano. Una naturaleza a la que cabe explotar y a la que la sociedad acude con la finalidad utilitarista de extraer materias primas necesarias para su sustento, que terminarán acrecentando su riqueza y haciendo posible el desarrollo de su civilización.

Al argumentar Pérez de Ayala la necesidad de privilegiar esta visión utilitarista del entorno natural, acuden en su ayuda fuentes y sensibilidades artísticas a las que en aquellos años el escritor asturiano llegó a sentirse muy próximo. La de Gabriele D'Annunzio ${ }^{15}$, en primer lugar, a cuya autoría se deben algunas composiciones poéticas que moldearon de manera firme el que era, a fines de aquel verano de 1916, su mismo entramado intelectivo. Se produce, por ejemplo, la evocación de los versos del vate cuando la comitiva de periodistas enfila la ruta de las Dolomitas, bordeando el curso embalsado del río Cismon y cuyo aprovechamiento permite generar energía hidroeléctrica. Se potencia la descripción que da Pérez de Ayala de aquel paisaje con el recuerdo explícito de aquellas composiciones en las que D'Annunzio pondera su admiración por quienes son capaces de extraer "de la antigua fuerza del agua la nueva fuerza" (Pérez de Ayala, 1917: 164), que son palabras reformuladas a partir

\footnotetext{
15. Entre los pocos estudiosos que se han aproximado a la huella que ha dejado el poeta italiano en la obra de Ramón Pérez de Ayala se halla Vicente González Martín (1978: 92 y ss.).
} 
del recuerdo de Maia - Laus Vitae: La sirena del mondo (vv. 89-99) ${ }^{16}$.

Con la obra poética de D'Annunzio hilvana el asturiano su justificación utilitarista de la explotación de la naturaleza por parte del hombre (Pérez de Ayala, 1917: 164-165). En la prosa de nuestro escritor encuentran acomodo aquellos versos en los que el poeta italiano había fundido la admiración estética por el paisaje majestuoso de los montes alpinos, junto con la osadía de quienes cotidianamente mostraban tener el arrojo suficiente para desafiar la wilderness y cumplir hazañas portentosas en sus cumbres más altas (Pérez de Ayala, 1917: 165), tomando para ello como fuente directa los versos de Maia - Laus Vitae: L'Amore dei monti (vv. 3055-3063). Sin ningún tipo de titubeo, Pérez de Ayala se sumaba así a la admiración maravillada por la épica del superhombre ${ }^{17}$, que tan a menudo latía asimismo en la producción literaria de D'Annunzio y que le dio fundamento ideológico.

En la conciencia de Pérez de Ayala no causan pesadumbre los efectos del conflicto bélico en el ambiente alpino. No suscita en él ninguna contrariedad contemplar aquellos montes "hormigueados y pululados por un ejército de operaciones" (Pérez de Ayala, 1917: 169). Los valles "eclógicos" (Pérez de Ayala, 1917: 171), que es adjetivo que deriva de la arcádica égloga, comparten espacio con los campamentos militares que se han asentado en las hondonadas, sin que ello llegue a suscitar en el asturiano un mínimo malestar ni remordimiento de conciencia. No siente ningún desconsuelo porque todo haya quedado alterado en un entorno en el que hasta el silencio original del enclave alpino se ha quebrado,

16. Maia - Laus Vitae es el primero de los cinco libros de que se componen las Laudi (D'Annunzio, 1903). Por parte de Pérez de Ayala hay aún, al final del mismo capítulo (y de hecho con esta alusión concluye), una última mención a los versos de esta primera entrega de las Laudi, allí donde remite a: "Ah perché non è infinito / come il desiderio, il potere / umano?" (vv. 87-89).

17. Se recordará que Pérez de Ayala fue un entusiasta divulgador del ideario y obra de Friedrich Nietzsche (José Ramón González 1993: 22). Para el influjo que el filósofo alemán ejerció sobre los componentes de la Generación de 1914, remitimos al estudio clásico de Sobejano (1967: 487-618). ahora que esa quietud ha quedado pulverizada por el eco de los cañonazos que reverbera de uno en otro valle (Pérez de Ayala, 1917:169). Ningún sentimiento de repulsa por la acción militar de los italianos que han llegado al extremo de la voladura de una montaña cuya cumbre se había convertido en bastión de los enemigos, aludiendo con ello a las vicisitudes de la empresa bélica del Castelletto (que describirá pormenorizadamente) y que tanta admiración le suscitó.

Sólo las cumbres más altas de las Dolomitas, aquellas que pese a la acometida de los hombres han permanecido por el momento invioladas, se permiten el capricho de mirar con displicencia al hombre y a su obra, de acuerdo con cuanto expresa en un poema de propia autoría que intercala, de manera desconcertante, en el interior del reportaje periodístico: “[...] legión de montañas, / seres apocalípticos e ingentes, / que desdeñan, con muecas hurañas, / a los hombres, microscópicos entes. / Entes ridículos y vanidosos / que aspiran a tiranizar la tierra" (Pérez de Ayala, 1917: 172). Es, como se ve, una lucha entre iguales, entre seres vivos que se desafían en combate y en cuyo transcurso las montañas se permiten desdeñar "con muecas hurañas" a los diminutos hombres que aspiran a imponer su voluntad también sobre estos titanes de piedra.

Hay, por parte de Ayala, un deliberado propósito retórico antropomórfico, al cabo del cual consigue dar ilusorios rasgos humanos a la montaña alpina. Cuando la comitiva se dirige en automóvil a las estribaciones dolomíticas, teniendo por base logística el establecimiento de Vena d'Oro, próximo a Belluno, en el que recala la comitiva de reporteros españoles, el ruido del vehículo consigue despertar, dar aliento humano, a aquel paisaje otrora inerte y que reacciona ahora como el recién nacido al que el ronroneo del motor ha despertado: si al principio los pequeños valles dormían, ahora abren ya sus párpados (o sea, las ventanas de las casas de campo ante las que pasan) y desperezan sus brazos (es decir, los campanarios de las iglesias que avistan desde su vehículo) (Pérez de Ayala, 1917: 163). El recurso a la metáfora antropomórfica constituye una estrategia retórica que no es nada nueva en la producción de Pérez de Ayala y que registramos con cierta reiteración ya en $T C$, toda vez que intenta aproximarse a la naturaleza y pretende circunscribir el potencial 
de su fuerza oscura en una estampa que sólo en apariencia es idílica (TC: 245):

La gravedad del paraje, desolado y agreste; la tristeza del cielo, por negras y cárdenas nubes formado; el lamentar del aire entre las ramas de unos árboles cercanos y el melancólico reír de un arroyo oculto que, por lo quebrado e inquieto de su voz, parecía alejarse saltando de peña en peña [...].

Si todo cuanto toma una dimensión positiva se humaniza, si todo cuanto es digno de consideración se somete a una mutación de cuño antropocéntrico, nada desconcierta en cambio que el enemigo (y no su semejante latino) termine a su vez degradado y se limite a encarnar a un organismo primario.

\section{CONCLUSIONES}

Una década separa la redacción de Tinieblas en las cumbres (1907) y los artículos recogidos en Hermann encadenado (1917). Supone un breve e intenso intervalo en cuyo transcurso se produce el tránsito ideológico del escritor asturiano, que manifiesta en sus primeras obras una visión clásica y humanista del paisaje, en la que vislumbramos el retorno a la relación que los autores de la latinidad establecieron con su entorno natural, hasta llegar a los textos nacidos al arrimo de la Gran Guerra y en los que advertimos una aproximación intelectual teñida por un marcado etnicismo. Cuanto en su novela juvenil se vinculaba a la contaminación del hábitat natural por parte del individuo procedente de la metrópoli era, en aquellas páginas, descrito con horror y aversión. Así la incursión del tendido ferroviario, símbolo quintaesenciado de una sociedad que se hunde a pico en la industrialización de la que el tren es elemento icónico, que avanza imparable por los valles asturianos y que torpedea el paisaje con su incesante sucesión de túneles que hieren las entrañas de los montes. Y así también la visión del establecimiento siderúrgico que, una vez ha arrancado el ferrocarril y ha dejado atrás la ciudad, refulge con sus llamaradas y con la luz violenta que despide el hierro colado en la oscuridad de la noche como "una especie de infernal decoración" (TC: 190), sobrecogiendo a los pasajeros que a bordo del ferrocarril se disponen a penetrar en la cadena de montañas. Es, a su vez, dicha fábrica un símbolo quintaesenciado de la sociedad industrial que se afianza incluso en los rincones geográficos más distantes, hiriendo a la naturaleza, allí donde aún en las laderas perviven las modestas cabañas de los campesinos y ganaderos de alta cota que viven armónicamente en aquel locus amoenus amenazado.

En los reportajes que Pérez de Ayala envió desde el frente italiano, y en los que se da noticia pormenorizada de cuantos acontecimientos bélicos se están produciendo a fines del verano de 1916 en las estribaciones alpinas y dolomíticas, la óptica del escritor asturiano muestra una alteración profunda. En ellos se intuye una metamorfosis radical con respecto a cuanto fantaseó en TC, diez años antes, sobre la ansiada comunión del individuo con la naturaleza primigenia. La identificación del reportero con la causa aliada le lleva no sólo a justificar, sino incluso a ensalzar, con entusiasmo propagandista, los destrozos que la maquinaria bélica de los italianos inflige al paisaje, moldeador de la raza, adoptando la actitud propia de un rehén ideológico sujeto al albedrío de uno de los bandos en conflicto. Pérez de Ayala nada censura en esta acción destructiva y todo queda, en cambio, justificado de manera plena y sin incertidumbres.

Es este un viraje intelectual que, como hemos visto, presenta elementos coincidentes (por lo demás admitidos de manera explícita por el escritor asturiano) con la producción poética de Gabriele d'Annunzio, quien afianza también sus raíces en el culto al superhombre de adscripción nietzscheana. Más que un bagaje cultural de valor trascendente, la asimilación al ideario del poeta decadentista tememos que constituirá para Ramón Pérez de Ayala todo un lastre ideológico que su experiencia directa de la guerra de montaña, a raíz de su labor como reportero en el transcurso del primer conflicto mundial, cataliza y provoca en él una llamativa metamorfosis ideológica. Aunque en fechas inmediatamente antecedentes el escritor asturiano se sitúa a distancia crítica del superhombre nietzscheano (en la novela poemática Prometeo [1915b] se plasma, de hecho, el fracaso de esta quimera), no puede al mismo tiempo resistirse a sentir la 
poderosa fuerza de atracción de este ideal que, como Andrés Amorós advirtió con acierto, "está unido a su tan querido tema de la educación y supone una clara alusión de tipo colectivo, nacional" (1972: 260).

Ramón Pérez de Ayala constituye, en definitiva, un paradigma del creador que pasa por numerosas contradicciones ideológicas y de cuyo choque caótico sale inesperadamente airoso y cargado con nuevos estímulos creativos. Por lo menos hasta 1926, año en que el componente de la Generación de 1914 puso voluntariamente final a su exquisita producción novelística. Al adentrarnos en su obra juvenil, al examinar la posición intelectual que adoptó ante la naturaleza en su interrelación con el individuo de la sociedad industrializada y al contraponer dicho ideario con la actitud que se desprende de los reportajes enviados desde el frente bélico italiano, palpamos el extravío con el que el narrador, poeta y ensayista asturiano se abría dificultosamente paso por entre la neblina en la que se halló sumida la Europa de entreguerras.

\section{BIBLIOGRAFÍA}

AMORÓS, A. (1972). La novela intelectual de Ramón Pérez de Ayala. Madrid: Gredos.

ARES, A. (2014). "Introducción y estudio preliminar", en Enrique Gil y Carrasco, Viajes y costumbres, Álida Ares (ed.). A Coruña: EBooks Bierzo, 13-72.

AZORÍN [MARTÍNEZ RUIZ, J.M.] (1917). El paisaje de España, visto por los españoles. Madrid: Renacimiento.

CANALS PIÑAS, J. (2016). "Paisaje y sociedad de alta montaña en De Madrid a Nápoles (1861) de Pedro Antonio de Alarcón", en Revista de Literatura, 155 (78), 95-118.

CANALS PIÑAS, J. (2017). Noticias desde el frente bélico italiano. Los reportajes de Enrique DíazRetg (1916 y 1917). Trento: Pubblicazioni del Dipartimento di Lettere e Filosofia.

COLETES BLANCO, A. (1984). Gran Bretaña y los Estados Unidos en la vida de Ramón Pérez de Ayala. Oviedo: I.D.E.A.

D’ANNUNZIO, G. (1903). Maia - Laus Vitae: La sirena del mondo. Milano: Fratelli Treves.

DÍAZ CANEJA, J. (1926). Paisajes de reconquista:
Un maravilloso rincón de España. Madrid: Talleres Calpe.

DOUGHERTY, D. (2012). "Descenso a los infiernos de la Gran Guerra: Pérez de Ayala en Italia”, en Javier Serrano y Amparo de Juan Bolufer (eds.), Ayaliana. Ensayos sobre la vida y obra de Ramón Pérez de Ayala en el cincuentenario de su muerte. Lugo: Axac, pp. 71-93.

GARRARD, G. (2004). Ecocriticism. Nueva York: Routledge.

GIACOMONI, Paola (2001). II laboratorio della natura. Paesaggio montano e sublime naturale in età moderna. Milano: FrancoAngeli.

GONZÁLEZ, A. (1981). "Ramón Pérez de Ayala: Verbalización del paisaje y credo estético", en Pelayo H. Fernández y McAllister H. Hull Jr. (eds.), Simposio internacional Ramón Pérez de Ayala (1880-1980). Gijón: Flores, 148-156.

GONZÁLEZ, J.R. (1993). Cómo leer a Ramón Pérez de Ayala. Madrid: Júcar.

GONZÁLEZ, J.R. (2012). “Texto, retórica e ideología en Herman encadenado: Ramón Pérez de Ayala, cronista de guerra", en Javier Serrano y Amparo de Juan Bolufer (eds.), Ayaliana. Ensayos sobre la vida y obra de Ramón Pérez de Ayala en el cincuentenario de su muerte. Lugo: Axac, 151-174.

GONZÁLEZ, J.R. (2016). "Visions/versions of the war: Ramón Pérez de Ayala and Juan Pujol on the Italian front", en Journal of Modern Italian Studies, 2 (21), 271-282.

GONZÁLEZ MARTíN, V. (1978). La cultura italiana en Miguel de Unamuno. Salamanca: Universidad de Salamanca.

HONRADO DE LA TORRE, L. (2016). “Deprisa y con lápiz: Entre la crónica periodística y el ejercicio literario. Notas a Hermann, encadenado, de Ramón Pérez de Ayala", en José Ramón González et al.(eds.): Testimonios del desastre: Periodistas y escritores en los campos de batalla. Gijón: Ediciones Trea, 99-128.

LEED, E.J. (1981). No Man's Land: Combat and Identity in World War 1. Cambridge: Cambridge University Press.

LEYRA SORIANO, A.M. (1998). "Literatura y realidad en las tres novelas poemáticas de la vida española de Ramón Pérez de Ayala", en José Carlos de Torres Martínez y Cecilia García Antón (eds.), Estudios de literatura española de los siglos XIX y XX: Homenaje a Juan María Díez Taboada. Madrid: CSIC, 559-568. 
LITVAK, L. (1991). El tiempo de los trenes. El paisaje español en el arte y la literatura del realismo (1849 - 1918). Barcelona: Ediciones del Serbal.

LOONEY, Lora L. (2004). “Unruly Bodies: Rereading Pérez de Ayala's First Novel, Tinieblas en las cumbres", en Anales de la Literatura Española Contemporánea, 29, 191-215.

MARTÍNEZ DE PISÓN, E., ÁLVARO, S. (2010). El sentimiento de la montaña. Doscientos años de soledad. Madrid: Desnivel.

McLOUGHLIN, K. (2009). "War in Print Journalism”, en Catherine Mary McLoughlin (ed.): The Cambridge Companion to War Writing. Nueva York: Cambridge University Press, 47-57.

NEGRETE PLANO, A. (2002). "Suiza y el paso de los Alpes en los recuerdos del Westmorland", en José María Luzón Nogué (ed.): El Westmorland. Recuerdos del Grand Tour. Sevilla: Fundación Cajasol, 107-117.

[PÉREZ DE AYALA, R.] (1915a). El señor de las batallas. Selección de discursos, cartas y telegramas de Guillermo II. Madrid: Imprenta Clásica Española.

PÉREZ DE AYALA, R. (1915b). Prometeo. Madrid: Los Contemporáneos.

PÉREZ DE AYALA, R. (1917). Herman[n] encadenado. Notas de un viaje a los frentes del Isonzo, la Carnia y el Trentino. Madrid: Imprenta Clásica Española.

PÉREZ DE AYALA, R. (1921). "Apostillas y divagaciones: Nietzsche (I)". La Pluma, 19, 321-336.

PÉREZ DE AYALA, R. (1922a). "Apostillas y divagaciones: Nietzsche (II)". La Pluma, 20, 1-18.

PÉREZ DE AYALA, R. (1922b). "Apostillas y divagaciones: Nietzsche (y III)". La Pluma, 21, 65-77.

PÉREZ DE AYALA, R. (1926). "Reconquista del paisaje", en Juan Díaz Caneja: Paisajes de Reconquista: Un maravilloso rincón de España. Madrid: Talleres Calpe, 45-51.

PÉREZ DE AYALA, R. (1971). Tinieblas en las cumbres, Andrés Amorós (ed.). Madrid: Castalia.

PETRARCA, F. (1978). Obras. I. Prosa, Francisco Rico (ed.). Madrid: Alfaguara.

SOBEJANO, G. (1967). Nietzsche en España. Madrid: Gredos.
VIERA Y CLAVIJO, J. (1849). Estracto de los apuntes del diario de mi viaje desde Madrid a Italia y Alemania. Santa Cruz de Tenerife: Imprenta, Litografía y Librería Isleña. 